\title{
INFLUENCE OF HIGH POWER LASER BEAM ON PHYSICAL PROPERTIES OF EPITAXIAL FILMS OF $\mathrm{Hg}_{1-x} \mathrm{Cd}_{x} \mathrm{Te}(x \approx 0.2)$
}

\author{
M. Kuźma, C. Abeynayake, \\ Institute of Physics, Higher Pedagogical School \\ ul. Rejtana 16a, 35-311 Rzeszów, Poland
}

E. Sheregil and I. VirT

Section of Experimental Physics, Pedagogical Institute Gogol 34, 293-720 Drogobich, Ukrainian SSR, SU

\begin{abstract}
Models have been proposed explaining differences in electrophysical and photoelectrical properties of epitaxial films of $\mathrm{Hg}_{1-x} \mathrm{Cd}_{x} \mathrm{Te}(x \approx 0.2)$ before and after treating by single pulses of Nd:YAG laser. These models were obtained on the basis of the calculated distributions of temperature, temperature gradient and concentration of interstitial mercury during and after exposing to the laser pulse. These calculations were done using the net method.
\end{abstract}

PACS numbers: $73.60 . \mathrm{Cs}, 81.40$. Rs

In order to achieve the desired stable parameters of $\mathrm{Hg}_{1-x} \mathrm{Cd}_{x} \mathrm{Te}$ (MCT) a heat treatment of the material using high power laser pulses is often used nowadays [1]. However, the physical nature of the influence of the laser beam on properties of the material remains unclear. The authors of Ref. [1] restricted their analysis to the qualitative aspect of the dynamics of atoms of one of the ingredients (mercury). This paper interprets the obtained experimental results on the basis of a computed spacio-temporal distributions of the temperature and the temperature gradient, taking quantitative mercury concentration distribution models into account.

Films of $p$-type MCT with thickness of $30 \mu \mathrm{m}$ were prepared on highly resistive substrates of $\mathrm{CdTe}$ by liquid phase epitaxy. Initial concentration and the mobility of charge carriers (heavy holes and electrons) measured at $T=$ $77 \mathrm{~K}$ by the method described in [2] were: $p=2.6 \times 10^{16} \mathrm{~cm}^{-3}, n=1.5 \times$ $10^{12} \mathrm{~cm}^{-3}, \mu_{\mathrm{p}}=200 \mathrm{~cm}^{2} / \mathrm{Vs}, \mu_{\mathrm{n}}=31000 \mathrm{~cm}^{2} / \mathrm{Vs}$. At room temperature the intrinsic carrier concentration and mobility were measured to be, respectively, 
$n=2.5 \times 10^{15} \mathrm{~cm}^{-3}, \mu_{\mathrm{n}}=4000 \mathrm{~cm}^{2} /$ Vs. After the irradiation with a pulse $(250 \mu \mathrm{s})$ of Nd:YAG laser $(\lambda=1.06 \mu \mathrm{m})$ having energy density $1.6 \mathrm{~J} / \mathrm{cm}^{2}$ the parameters of the carriers were changed as follows: at $T=77 \mathrm{~K} p=6.4 \times 10^{16} \mathrm{~cm}^{-3}$, $n=9.0 \times 10^{11} \mathrm{~cm}^{-3}, \mu_{\mathrm{p}}=120 \mathrm{~cm}^{2} / \mathrm{Vs}, \mu_{\mathrm{n}}=68000 \mathrm{~cm}^{2} / \mathrm{Vs}$, and at $T=300 \mathrm{~K}$ $n=6 \times 10^{16} \mathrm{~cm}^{-3}$ and the mobility was decreased by a factor 100 . After the irradiation with a single pulse with the above mentioned value of the energy density, a persistent rise of the resistance was observed (Fig. 1). According to the photo-

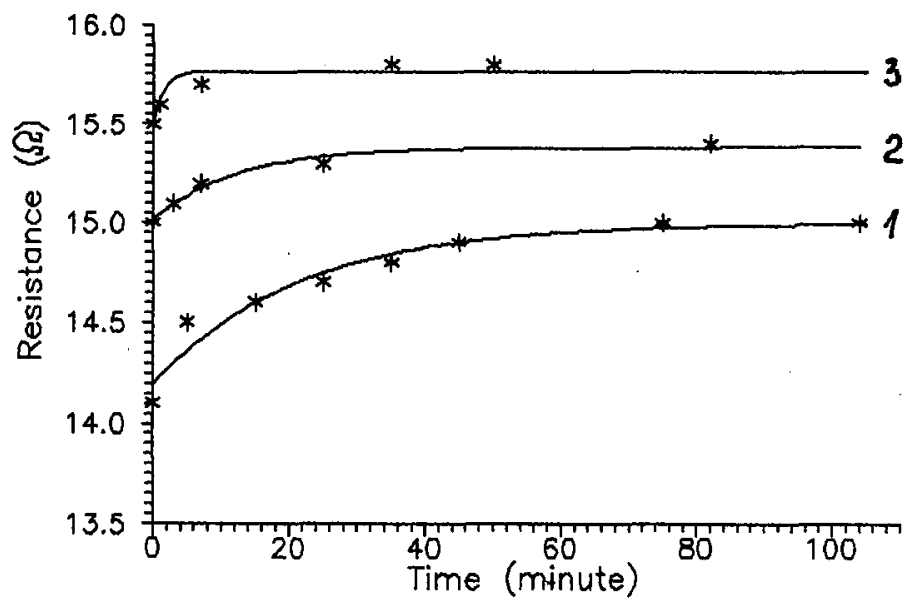

Fig. 1. Resistance of the epitaxial film as a function of time after laser treatment: curve 1 - after the $1^{\text {st }}$ pulse having energy density $1.6 \mathrm{~J} / \mathrm{cm}^{2}$, approximated by the function $R(t)=R_{0}+R_{1}(1-\exp (-t / \tau))$ with $R_{0}=14.2 \Omega, R_{1}=0.8 \Omega, \tau=21.4 \mathrm{~min}$, curve 2 - after the $2^{\text {nd }}$ pulse having the same energy density and approximated by the same function with $R_{0}=15.0 \Omega, R_{1}=0.4 \Omega, \tau=12 \mathrm{~min}$, curve $3-$ after the $3^{\text {rd }}$ pulse, $R_{0}=15.5 \Omega, R_{1}=0.3 \Omega, \tau=1.5 \mathrm{~min}$.

conductivity measurements there are two peaks in the spectral distribution of the photoconductivity of the films prior to irradiation: at $10.5 \mu \mathrm{m}$ and $8.5 \mu \mathrm{m}$. After exposing to six laser pulses, only the peak at $9.5 \mu \mathrm{m}$ remains. This phenomenon can be interpreted as a result of a homogenization of the material. The long wavelength edge of photoconductivity coincides well with the activation energy in the range of an intrinsic electroconductivity $(0.11 \mathrm{eV})$.

The most significant effect occuring during the laser annealing is a nonhomogeneous (in space and in time) heating of the specimen. For the case of a thin film $(30 \mu \mathrm{m})$ having uniformly irradiated surface, an one-dimensional approach is quite acceptable. In this situation the thermoconductivity equation was solved by the net method [3] with the following initial and boundary conditions: $T(x, 0)=300 \mathrm{~K}$, $\partial T(0, t) / \partial x=0, T(l, t)=300 \mathrm{~K}$ (l-thickness of the film and the substrate, taken together). It was also assumed that there was no abrupt change in the temperature at the boundary between the film and the substrate. Results of the calculations 
for a distribution of the temperature and the temperature gradient are presented in Fig. 2a and 2b, respectively.
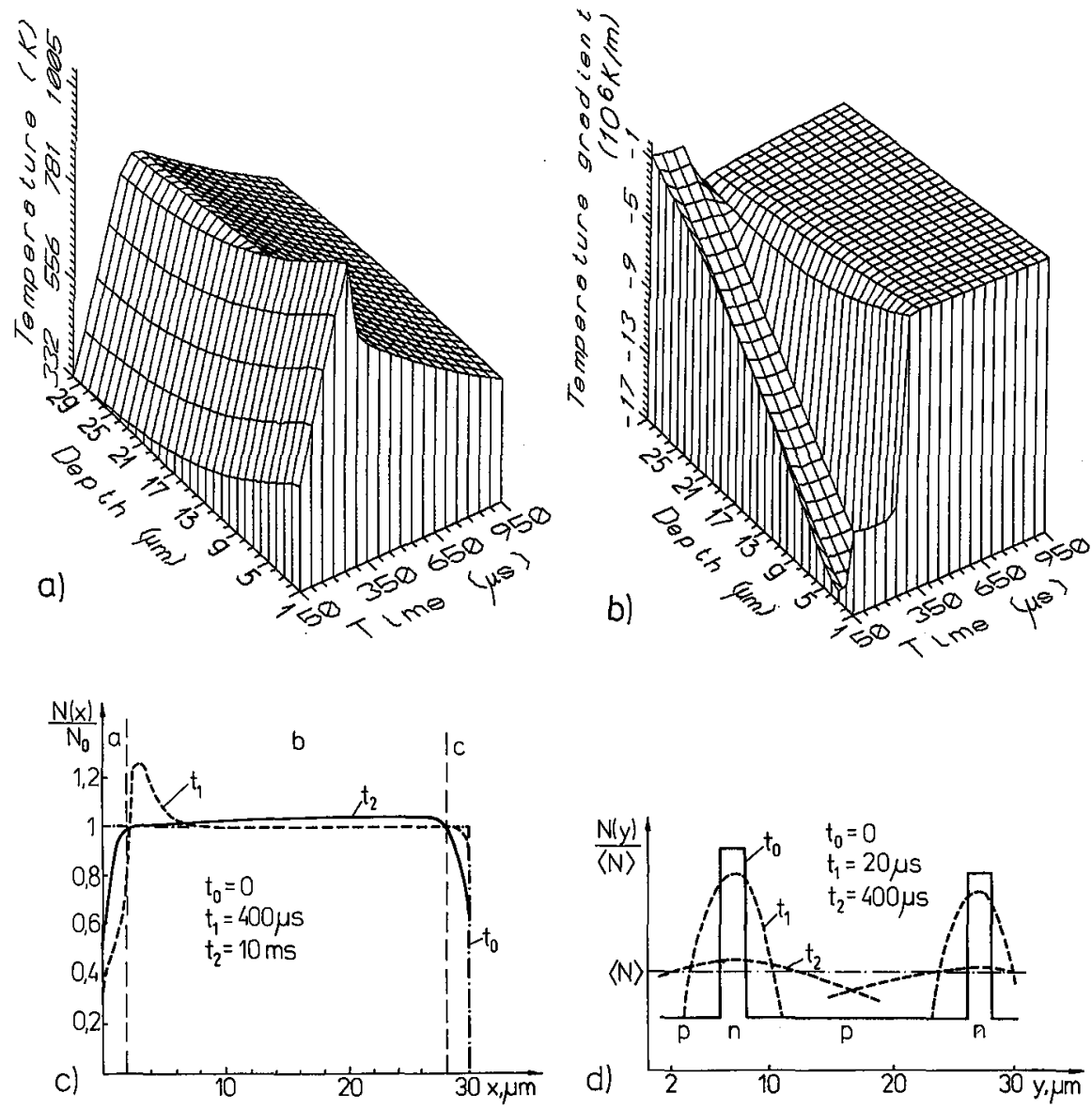

Fig. 2. Distribution in time and in space of: (a) temperature, (b) temperature gradient, (c) concentration of interstitial mercury along the depth of the film in the process of laser annealing, (d) microdistribution of interstitial mercury taking into account the two-cluster model before exposition (solid line) and during the process of laser annealing (dashed lines).

Rising the temperature in the near-surface layer up to $1045 \mathrm{~K}$ (i.e., slightly lower than the melting point of MCT) leads to a partial evaporization of mercury. Calculation according to the formula for the inverse diffusion (evaporization) [4] showed that the concentration of $\mathrm{Hg}$ was changed significantly only in the surface layer having thickness $0.5 \mu \mathrm{m}$.

Establishment of a new distribution of the concentration $N$ of the interstitial mercury is an another probable process which possibly occurs in the film 
under laser annealing. Calculations of this distribution were carried out by the net method using the following equation of the diffusion and assuming that the initial distribution was homogeneous:

$$
\frac{\partial N}{\partial t}=D \frac{\partial N}{\partial x^{2}}-\frac{D}{k T}\left\langle\frac{\tau_{\mathrm{f}}}{\tau_{\mathrm{f}}}\right\rangle C_{v} \frac{\partial^{2} T}{\partial x^{2}}
$$

where $\left\langle\tau_{\mathrm{f}} / \tau_{\mathrm{f}}\right\rangle$ is the average ratio of the relaxation time of phonons on atoms of the crystal lattice, $\tau_{\mathfrak{f}}$, to that of on the impurity 'atoms, $\tau_{\mathrm{f}}$ (in our case of interstitial mercury this ratio is nearly equal to 1$), C_{v}$ - specific (by volume) heat capacity (the values of these quantities were estimated according to the elementary volume of atoms of lattice and impurities [5,6] as well as from the thermal capacity for crystals). The last term in (1) represents the force acting on an interstitial mercury atom resulting from the phonon flow [5]. According to the results of the calculations for our specimen after cooling, presented in Fig. 2c the film can be divided into three layers: (1) near-surface layer, depleted of mercury and having relatively increased resistance $R_{a}(2)$ intermediate layer richer in mercury $\left(R_{b}\right.$ - less than inital $R_{0}$ ) and (3) a layer which is also depleted of mercury and correspondingly having an increased resistance $R_{c}$. Simple calculation shows that the total resistance of the film consisting of such layer should be decreased, which clearly contradicts the results of the experiment. From this it can be seen that the surface layer (having thickness $0.5 \mu \mathrm{m}$ ) should not affect the resistance of the sample and the final distribution of mercury.

For the last point, we consider how laser annealing can affect microdistribution of mercury. The experiment involving photoconductivity provides grounds to suggest that there may be two components of the photoconductivity. This agrees with two-cluster model of the conductivity of MCT crystals of $p$-type [7, 8]. According to [7], a modulation of the concentration of mercury has an amplitude about $7 \%$ and an average period of $25 \mu \mathrm{m}$. In Fig. $2 \mathrm{~d}$ a simplified model corresponding to such a distribution has been shown by a continuous line. A calculation according to the formula describing the diffusion in thin films [4] shows that the peak in the concentration forming $n$-cluster "spreads" up to $68 \%$ during the time which includes the pulse length and time needed for cooling down to $600 \mathrm{~K}$. In this manner the model explains the destruction of $n$-cluster (corresponding to the increase of the resistance) and homogenization of the specimen. But it is not sufficient to interpret the lasting increase of the resistance because the clusters are destroyed within $0.5 \mathrm{~ms}$ while the time needed for cooling the specimen down to the room temperature, at which the diffusion "freezes," is about $10 \mathrm{~ms}$.

From the above statement we may conclude that the most probable mechanism of significant changes of electrophysical and photoelectrical properties of the studied films due to the laser treatment is the micro-redistribution of mercury.

It can be assumed that dislocations can be the cause of the lasting increase of the resistance of the MCT film after exposing to a laser pulse. These dislocations must be generated by stress induced by a significant gradient of the temperature. It is known that the stress field which is left in the specimen after cooling accelerates the motion of dislocations in the given material even at the room temperature. 


\section{References}

[1] N.N. Vasiuk, A.A. Druzhinin, G.A. Ilchuk, R.V. Luciv, S.P. Pavlischyn, Ukr. Fiz. Zh. 28, 1218, (1983);

I.S. Virt, A.V. Lubchenko, P.E. Mozol, V.A. Gnatyuk, Fiz. Tekh. Poluprovodn. 23, 1386 (1989);

C.N. Afonso, M. Alonso, J.L.N. Neira, A.D. Sequeira, M.F. da Silva, J.C. Soares, J. Vac. Sci. Technol. A 7, 3256 (1989);

A.Baidullaeva, B.K. Dauletmuratov, V.A. Gnatyuk, P.E. Mozol, Phys. Status Solidi B 122, 243 (1990).

[2] J.O. Ugrin, E.M. Sheregii, Fiz. Tekn. Poluprovodn. 22, 1375 (1988).

[3] N.G. Kondrashov, N.V. Parljukievich, Isledovanija po teploprovodnosti, Ed. A.V. Leykov, Minsk 1967, p. 208.

[4] G.B. Abdulajev, T.D. Dzchafarov, Atomnaja difuziya v poluprovodnikovykh strukturakh, Moskwa 1980.

[5] V.B. Fiks, Ionnaja provodimost'v metallakh i poluprovodnikakh, Moskva 1969.

[6] V.P. Voronkov, G.A. Gurchenok, Fiz. Tekh. Poluprovodn. 24, 1831 (1990).

[7] L.D. Saginov, V.A. Fedorenko, V.I. Stafeev, V.P. Ponomarenko, V.L. Jegorov, Fiz. Tekh. Poluprovodn. 16, 1256 (1982).

[8] V.I. Ivanov-Omskii, N.N. Berchenko, A.I. Elizarov, Phys. Status Solidi 103, 11 (1987). 